artigo $]$

[MARIA TERESA LOPES]

Doutora pela Universidade Federal de Pernambuco (UFPE); líder do Grupo de Estudos em Formação do Olhar (GeFol/UFPE); professora adjunta de Design (CAA/UFPE).

teresa.designer@gmail.com

[NATÁLIA CRISTINA PEREIRA BARBOSA]

Bacharel em Design pela Universidade Federal de Pernambuco (UFPE); filiada à Rede Internacional de Design/Educação (Ride/UFPE).

tatinhabarbosa@gmail.com

\title{
A exclusividade é o luxo recifense': um estudo sobre o processo de significação dos conceitos de luxo e popular pelos designers da capital pernambucana
}

\section{The exclusivity is the luxury of Recife's city Designers: a study of the process of signification of concepts luxury and popular by designers from the capital of Pernambuco}

[resumo] Entender o luxo em determinado tempo e ambiente tornou-se uma tarefa complexa, mas, ainda assim, indispensável à formação de designers, visto que o seu estudo pode revelar não apenas necessidades de mercado e anseios sociais, mas também aspectos dos valores vigentes na cultura visual. Assim, esta pesquisa apresenta como objeto de estudo os designers recifenses e tem como objetivo principal entender como eles significam material e simbolicamente os conceitos de luxo e popular e decantam esse imaginário em artefatos, tomando como parâmetro o entendimento do design de moda como um processo de impregnação de significado sobre os artefatos e também como vetor para a inovação.

[palavras-chave $]$

design de moda; designers recifenses; luxo; popular; materialidade.

[abstract] Understanding the luxury at one time and environment has become a complex task, but at the same time essential, training designers, since their study may reveal not only market needs and social aspirations, but also aspects of the values prevailing in the visual culture of a society. So this research presents as the object of study recifenses designers and aims to understand how they mean materially and symbolically the luxury concepts and popular, and decant this imaginary artifacts, taking as parameter the understanding of fashion design as a means of impregnation process also as vector for innovation. 


\section{INTRODUÇÃO}

0 estudo que ora é apresentado é o resultado de três anos de trabalho na pesquisa intitulada Mapeamento do potencial inovador do APL de confecção do Agreste pernambucano, tendo como conhecimento de base para a inovação o design de moda, financiada pelo CNPq entre os anos de 2013 e 2015, e que se encontra em fase de relatoria, prestação de contas e extensão. Essa pesquisa foi realizada em oito cidades do Agreste - Caruaru, Bezerros, Gravatá, Poção, Pesqueira, Passira, Santa Cruz do Capibaribe, Toritama - e em uma do litoral pernambucano, Recife. Foi executada com a participação de oito bolsistas.

0 estudo liderado pela professora Teresa Lopes, no Grupo de Estudos em Formação do Olhar ${ }^{2}$, teve como objetivo entender como o design de moda pode atuar como um vetor de ordenação de novos objetos na região Agreste, nesse caso fazendo um contraponto geopolítico, entre as ordens significativas luxo e popular, relacionadas, respectivamente, a estar no Recife (capital) e no Agreste (interior), ordenando para isso a pergunta de pesquisa: Como os designers recifenses significam material e discursivamente os conceitos de luxo e popular em seus produtos de moda?

A pesquisa foi assim desenhada por ter-se alavancado o campo significativo do luxo, como uma alternativa para inovar, mudar o "sentido aparente" dos produtos de moda produzidos na região Agreste, que comporta o Arranjo Produtivo de Confecção do Estado, e por entender design de moda como um processo de impregnação de significado sobre os artefatos. 0 resultado desse estudo é que capital e Agreste são dimensões complementares das ações constitutivas para se produzir objetos de moda - Recife como polo criador e 0 Agreste como produtor -, mas não dialogam do ponto de vista do design, comungando apenas, na melhor das hipóteses, das trocas simbólicas de imagens midiatizadas das festas juninas.

Um fato muito peculiar, nesse contexto, é que se por um lado os designers recifenses, na sua grande maioria, não produzem suas criações no Agreste, na outra mão, eles produzem um campo simbólico que inclusive é determinante do conceito de luxo no Estado, e que curiosamente acomoda, e muito, a dimensão popular dos objetos que são feitos no interior do Estado.

Esse argumento comprova que o luxo pode sim ser uma saída para a inovação na moda pernambucana, mas para isso de fato acontecer, esse conceito, antes de tudo, precisa ser pauta de discussão e, principalmente, ser entendido como uma dimensão simbólica possivel e desejável para a região Nordeste, um contexto muito raro para a realidade atual da região.

Assim, entendeu-se que há o discurso ${ }^{3}$, o desejo e o imaginário para o diálogo, mas a prática é reveladora de que a distância entre as duas regiões é muito maior do que apenas aquela que a BR 232, que liga a capital à região, separa. Existe a intenção, mas ainda falta a concretude, faltam ecossistemas que estabilizem a relação de criação e de produção como algo comum e construtor, por exemplo, do desenvolvimento social e econômico do Estado.

Nesse entendimento e desejo de mudança, a pesquisa convocou o design como um conhecimento que se posiciona como um baricentro - um campo de forças para o qual converge a relação entre o luxo e o popular -, notadamente na ordem glocal ${ }^{4}$ que ora é vigente, quando se discute o que é luxo para os designers na cidade do Recife (Estado de Pernambuco - Brasil), em oposição ao sentido de popular, nesse caso, o que é produzido em grande parte no Agreste.

Assim, enxergamos o design como um forte fator estratégico dentro do atual panorama da nossa sociedade (assim como os conceitos de luxo e de popular) e, notadamente, no campo da moda - no qual situa-se a discussão 
que se apresenta -, pois ele, desde que o evangelho do design thinking foi inaugurado por Tim Brown, a inovação como atividade do design vem se tornando uma negociação discursiva que cada dia toma mais força e acaba por atribuir, ao campo do design, a responsabilidade de estruturador no novo, e por conseguinte, determinante do prescrito.

Para tanto, a primeira parte deste trabalho constitui-se de uma pesquisa de campo na qual foram realizadas 24 entrevistas (registros audiovisual e fotográfico), com os empresários, donos de marcas recifenses de moda. Os ateliês escolhidos tinham que preencher os requisitos de produzir artefatos de criação e estilo próprios, ou seja, o setor de moda autoral - aqui adotamos, para moda autoral, as características cunhadas por Garcia e Miranda (2005, p. 57), que "[...] reforça ideais que vão contra o mercado clássico de moda, a saber: não se baseiam em tendências ditadas por birôs de estilo, valorizam a autenticidade do produto, visam à pequena escala, além do uso de materiais locais e processos manuais (artesanais) no seu desenvolvimento" -, cujas lojas ou ateliês são originários da cidade do Recife.

Sob um olhar qualitativo, as entrevistas - as falas - realizadas apresentaram uma discussão que aprofunda o campo do design de moda, confirmando-o como um conhecimento para inovação e produção de artefatos de luxo contemporâneo. Fazendo isso com base em uma análise de significação ${ }^{5}$, que parte da premissa de como localmente os designers da cidade do Recife compreendem seus produtos como artefatos de luxo, contudo, fazendo-os refletir esse lugar a partir da interpolação valorativa e opositora entre o luxo e o popular.

Contudo, nessa pesquisa, quando o termo popular foi utilizado nas entrevistas, optou-se por não usar nenhum tipo de definição, como uma maneira de deixar livre a interpretação dos próprios entrevistados. Em geral, as interpretações caminharam para duas direções: a primeira remetia aos designers o entendimento de produção em massa, ao barato, ao que está em moda e por causa disso se torna massificado; em um segundo campo, remetia ao que historicamente tem uma origem popular, um saber fazer que vem de um povo, como o bordado, a renascença, 0 artesanato em geral.

Por fim, pode-se fazer a discussão de que a relação entre luxo e popular é uma dimensão de significação da moda para a cidade do Recife, e para os seus designers os conceitos referentes aos dois termos não vêm dissociados, de forma que algo que é popular pode sim ter valor de luxo e vice-versa, contanto que os artefatos criados possuam, acima de tudo, exclusividade de estilo/aparência e qualidade na sua produção. Porém, o popular, para esses designers, vem como algo particularizado pelo branding da marca, ou seja, cada marca constrói uma nova significação em cima do termo, trazendo-o para dentro da sua identidade, não visto como algo menor aos discursos predominantes, mas sim como algo que os configura como originais e únicos. Dessa maneira, esses designers estão (re) significando o valor de popular e, por conseguinte, vêm (re)significando também os valores estéticos presentes na região.

\section{O termo popular e seu sistema de significados}

Iniciaremos argumentando sobre os dois eixos centrais da discussão proposta, o luxo e seu campo de significação e o popular, fazendo essa relação até o ponto em que ela se encontra com o design. Essa discussão começa pelo sistema de significados que esteticamente mais caracteriza a região Agreste, a dimensão popular e, em seguida, com maior fôlego, pois esse é o maior interesse aqui, apresenta-se o termo luxo, para se concluir com a relevância para o design e a moda.

Em um entendimento que parte do senso comum e se apoia na raiz latina do termo - populãris -, a palavra popular é um adjetivo que caracteriza aquilo que pertence ou é relativo ao povo ${ }^{6}$. Definição esta que por si só é capaz de admitir 
várias interpretações dentro do mesmo universo de significados. De fato, pode-se entendê-la como aquilo que provém do povo, que é próprio das classes sociais menos favorecidas, mas também e frequentemente quando associada a objetos remete a algo relativo ao preço, como barato ou acessivel, que pode ser encontrado ao alcance da maioria - é dirigido às massas consumidoras - ou é conhecido pela sociedade em geral.

Mas esse tipo de conceituação é relativizada dentro de um senso comum, que ora nos é interessante por encontrar eco na fala de nossos entrevistados, mas torna-se superficial diante da discussão apresentada. Assim, se buscamos nos autores do campo da análise social o termo popular, pode-se observar que a ocorrência desses dois tipos de definições (apresentadas acima) são colocadas também por Hall (2003) em um capitulo do seu livro Da diáspora, no qual o autor realiza uma desconstrução em relação ao termo popular, incluindo notas de pensamentos sobre os seus possíveis significados:

\begin{abstract}
Em seguida, quero falar um pouco sobre "popular". 0 termo pode ter uma variedade de significados, nem todos eles úteis. Por exemplo, o significado que mais corresponde ao senso comum: algo é "popular" porque as massas o escutam, compram, leem, consomem e parecem apreciá-lo imensamente. Essa é a definição "comercial" ou "de mercado" do termo: aquela que deixa os socialistas de cabelo em pé. E corretamente associada a manipulação e ao aviltamento da cultura do povo. (HALL, 2003, p. 247)
\end{abstract}

Em consonância com o pensamento de Hall, apresenta-se aqui a fala de Canclini (2006), também em relação a esse significado do termo popular:

A noção de popular construída pelos meios de comunicação, e em boa parte aceita pelos estudos nesse campo, segue a lógica do mercado. "Popular" é o que se vende maciçamente, o que agrada a multidões. A rigor não interessa ao mercado e à mídia o popular e sim a popularidade. (CANCLINI, 2006, p. 260)

Dando continuidade aos relatos de Hall, após articuladas críticas sobre esse primeiro significado, o autor continua:

A segunda definição do "popular" é mais fácil de se aceitar. É mais descritiva. A cultura popular é todas essas coisas que "o povo" faz ou fez. Esta se aproxima de uma definição mais "antropológica" do termo: a cultura, os valores, os costumes e mentalidades [folkways] do "povo". Aquilo que define seu "modo característico de vida" (HALL, 2003, p. 248).

E pondera sobre o raso sentido descritivo dessa definição:

[...] Não podemos simplesmente juntar em uma única categoria todas as coisas que "o povo" faz, sem observar que a verdadeira distinção analítica não surge da lista - uma categoria inerte de coisas ou atividades - mas da oposição chave: pertence/não pertence ao povo. Em outras palavras, o princípio estruturador do "popular" 
nesse sentido são as tensões e oposições entre aquilo que pertence ao domínio central da elite ou da cultura dominante e a cultura da "periferia". É essa oposição que constantemente estrutura o domínio da cultura na categoria do "popular" e do "não-popular". [...]

0 que importa então não é o mero inventário descritivo - que pode ter o efeito negativo de congelar a cultura popular em um molde descritivo atemporal, mas as relações de poder que constantemente pontuam e dividem o domínio da cultura em suas categorias preferenciais e residuais. (HALL, 2003, p. 256)

A exemplo da importância sobre a análise da oposição das classes para se entender o sentido de popular na fala de Hall, destaca-se aqui a fala de Santos (1996) quando se refere ao significado de cultura popular:

\footnotetext{
Entende-se então por cultura popular as manifestações culturais dessas classes, manifestações diferentes da cultura dominante, que estão fora de suas instituições, que existem independentemente delas, mesmo sendo as duas contemporâneas. É importante ressaltar que é a própria elite cultural da sociedade, participante de suas instituições dominantes, que desenvolve a concepção de cultura popular. Esta é assim duplamente produzida pelo conhecimento dominante. Por um lado, porque na formação de seu próprio universo de legitimidade, muitas manifestações culturais são deixadas de fora; por outro porque é o conhecimento dominante que decide o que é cultura popular. (SANTOS, 1996, p. 55)
}

Para complementar a fala de Santos (1996), pode-se convocar Catenacci (2001), que diz que cultura popular é, ao mesmo tempo, produto de um contexto determinado e de um diálogo sobre as questões colocadas por ele, os objetos que dão sentido à cultura popular são reflexo não somente da imaginação das pessoas, mas de sistemas de exclusão social, negligências de acesso à educação e à cultura e, notadamente, da desigualdade na distribuição de renda.

No campo da arte, o termo popular tem uma dinâmica bem contrastante, quando pode-se observar que a sua significação varia de um extremo ao outro, de uma expressão estética "menor" até o termo "arte popular", que toma esse tipo de criação como inerente ao fruir, estruturando um sistema de significação que pendula da não arte à arte em instantes de um tempo discursivo.

0 sentimento ou o artefato ligado à arte popular são feitos por pessoas que, na maioria dos casos, possuem poucos recursos financeiros e/ou não receberam formação para tal atividade, normalmente estão vivendo na periferia de grandes cidades ou mesmo no interior do país, contam com a expressão artística como forma de significar para si e para o mundo e quase sempre dependem dessa atividade para viver. Assim, pode-se entender que tipo de objeto se produz na região Agreste, quando ele está sendo classificado como popular.

Esse objeto, resumidamente, seria algo que dialoga em muitos sentidos com o campo da arte, mas que o sistema de produção ao qual ele está vinculado está muito distante do que o design conforma. E, nesse sentido, a oposição discursiva e conceitual entre luxo e popular, aqui, não é opositiva no sentido de denegrir a segunda em relação à primeira, não é uma ordem absoluta e sintética, mas sim coloca o primeiro como algo que difere do segundo, e que, assim, pode funcionar como um corte de inovação, sendo um campo possível de novos sentidos para o outro.

É interessante frisar que luxo e popular são campos de significações (ainda imateriais) para a discussão da atuação do design como um conhecimento para inovação, e não como um espaço para se dar sentido ao preconceito ou qualquer 
outro significado que vise denegrir ou diminuir a dimensão "popular" na realidade. Assim, buscou-se a justificativa para estudar o campo de significações que se abriram ao se confrontar o entendimento dos termos popular e luxo, um em relação ao outro, como uma forma de se compreender as potencialidades de inovação para o design em Pernambuco.

É importante observar que essa oposição, algo que na modernidade era tão claro, dual e distintivo, inclusive de classes sociais, sendo algo estabilizado social e culturalmente, passa, com a contemporaneidade, dentro de uma ação objetiva (produção de artefatos de moda), por uma rarefação discursiva que fragmenta o luxo e o popular em uma progressão geométrica de sentidos, que permite, inclusive, a igualdade e o popular dentro de um sentido de luxo, como é o caso dos designers recifenses.

Por fim, sendo isso possivel, pois esses designers mesclam em seu imaginário e decantam em seus produtos valores, ordens simbólicas conformadoras de uma região - Pernambuco -, sua localidade, com um sistema de distinção ${ }^{7}$ aspiracional de individualidade, unicidade e exclusividade, e, para que isso se materialize, acionam um argumento global (exclusivo) para organizar sua produção.

\section{Sobre o luxo e seus tantos significados}

Antes de começar a discussão sobre as definições que cercam o termo luxo, é importante frisar que a argumentação teórica aqui articulada conta com o trabaIho de duas autoras: Galhanone (Atitudes, emoções e comportamento de compra: um estudo com consumidores de produtos de luxo ou sofisticados, 2008) e Toraci (Tiaras são para sempre: significação de luxo na vida cotidiana, 2010), cujos estudos foram essenciais para o desenvolvimento de nossos argumentos, visto que discutem o luxo dentro de um sistema de significação no qual a brasilidade desse sentimento é alvo de suas discussões. Nesse sentido, o que é apresentado aqui colabora para o campo de entendimento de como o "luxo" pode ser algo brasileiro.

É curioso entender que, com o passar do tempo, os significados atribuídos aos artefatos de luxo foram se transmutando e no atual século não são vistos mais como conformadores de determinadas classes sociais, mas como organizadores dos propósitos aparentes de um público mais heterogêneo: "Sua variedade de ofertas e formas de consumo reflete a própria diversidade da sociedade" (D'ANGELO, 2006, apud GALHANONE, 2008, p. 19).

0 gosto pessoal é mais forte que as convenções sociais: "Hoje, o luxo está mais a serviço da promoção de uma imagem pessoal do que de uma imagem de classe" (LIPOVETSKY; ROUX, 2005 apud GALHANONE, 2008, p. 20). Ainda, segundo a autora:

Esse espirito de liberdade presente nos dias de hoje que leva ao consumidor a manter uma relação mais afetiva e emocional com os objetos luxuosos, mais dependente das sensações pessoais do que do desejo de distinção social; seria um luxo inédito, emocional, intimo, a serviço do indivíduo e de suas sensações subjetivas. (GALHANONE, 2008, p. 20)

A partir do desenvolvimento desse tipo de pensamento - oriundo de fenômenos como a democratização do luxo, a elevação do padrão de vida das classes médias e a globalização -, acomoda-se como significado um novo segmento do mercado: o novo luxo. Vinculado não só ao enriquecimento material, esse moderno conceito também traduz a ruptura trazida pela difusão, nas sociedades demo- 
cráticas e individualistas, da aspiração generalizada à felicidade material e ao bem viver (os múltiplos hedonismos do presente global).

Os clientes desse novo mercado vêm trocando o conceito da exclusividade negativa (referente ao luxo tradicional) pelo da individualidade. Eles querem produtos que sejam a sua cara, que mostrem o seu estilo e a sua identidade e que, ao mesmo tempo, os façam se sentir únicos. "Buscam benefícios genuínos e diferenças reais, aspectos criados não somente pelo marketing, mas por todas as disciplinas gerenciais" (SILVERSTEIN \& FISKE, 2005 apud GALHANONE, 2008, p. 118).

E por que é importante, para o campo do design, estudar esses mercados (luxo e novo luxo)? Segundo Lipovestky \& Roux (2005), os objetos luxuosos correspondem à expressão dos desejos e das emoções humanas, por meio deles pode-se conhecer um pouco dos valores, crenças e atitudes das pessoas que os consomem. Ao mesmo tempo, o universo do luxo dá indícios sobre os sistemas de valores e a visão de mundo compartilhada pelos diversos grupos sociais, sendo, assim, um campo de variados objetos de investigação, quando se deseja entender esses grupos pela análise da significação.

0 termo luxo apresenta vários significados que, embora semelhantes, não se igualam, e sim se complementam. 0 desafio em relação ao estudo do luxo começa na conceituação do termo, pois este apresenta, além de muitos sentidos concretos (raridade, escassez, alta qualidade), valores subjetivos e simbólicos.

Etimologicamente, verifica-se que a origem da palavra luxo é contraditória. Segundo Kapferer (2003), o termo vem do latim lux, que significa luz, e isso explicaria características típicas dos objetos ditos de luxo: o luxo brilha e tem uma queda pelo ouro, pelas pedras e pelos brilhantes; por extensão, cada objeto torna-se quase uma joia em si. Por outro lado, para Castarède (2005), luxo vem do latim luxus (abundância, refinamento), e não lux, o que teria induzido alguns a identificá-lo à luz que ilumina o mundo.

Para Lipovetsky \& Roux (2005, p. 115), o "luxo é também derivado de luxus oriundo do vocabulário agrícola, que inicialmente significou "o fato de crescer de através", depois "crescer em excesso", para tornar-se "excesso em geral" e, enfim, significar "luxo" a partir do século XVII". Ainda, segundo os mesmos autores, entre os derivados de luxus encontram-se igualmente luxúria, exuberância, profusão, luxo e vida mole e voluptuosa.

0 que se pode entender, entretanto, é que independentemente da origem real da palavra luxo, o seu significado apresenta valores que sempre irão remeter à utilização do termo como qualidade, raridade, distinção, prestígio, exuberância. Além de possuir muitos significados, o conceito de luxo também muda de acordo com a sociedade e a época e, principalmente, segundo as ideias de necessidades ou comodidades básicas que se expandem ou redefinem.

"Um produto ou serviço pode migrar de categoria a partir do momento em que se torna acessivel para várias camadas sociais, deixando de representar uma distinção social ou bem de alto custo" (GALHANONE, 2008, p. 10).

Portanto, um bem ou produto em particular pode, com o passar do tempo, e a partir dos sistemas de significação aos quais ele está vinculado, passar de uma categoria a outra, podendo ser uma forma de se compreender como uma sociedade se organiza ao criar o seu sistema de distinção entre pessoas e estamentos.

Assim, é importante observar que, com a contemporaneidade, um novo cenário do mercado de luxo vem se apresentando na sociedade de consumo ocidental. Sobretudo uma mudança do chamado luxo tradicional, mais exteriorizado e com objetivos relacionados ao poder econômico, como status e reconhecimento, para um luxo cada vez mais interiorizado, o chamado novo luxo, o qual busca principalmente experiências prazerosas e questões relativas ao gosto, como também apontam Villaça \&t Castilho (2006) e Toraci (2010). 
Nesse sentido, complementa-se:

0 setor representado pelos produtos luxuosos vem reorganizando-se como um mercado diferenciado, diversificado, em que o luxo baseado em status coexiste com outro, intermediário e acessivel. "Não há mais um luxo, mas luxos, em vários graus, para públicos diversos." Dessa forma as expectativas e comportamentos relativos aos signos de prestígio transformaram-se em relações mais personalizadas, e mais próximas. (GALHANONE, 2008, p. 10)

Hoje, os objetos de luxo, em linhas gerais, não são valorizados simplesmente por sua função ou seu preço; 0 universo do luxo se vale, sobretudo, de símbolos. "0 luxo desenvolve o imaginário humano e é esta dimensão simbólica dos produtos que preenche de subjetivação o consumo contemporâneo" (TORACl, 2010, p. 11). "Portanto, o luxo escapa a definições simples e concretas e respira livremente na esfera mais rarefeita dos desejos, do prazer, do simbólico e da ambiguidade" (GALHANONE, 2008, p. 10).

No entanto, mesmo com o crescimento do consumo pelo desejo pessoal na atualidade, não podemos esquecer a importância da questão social de manifestação de riqueza e status. Segundo D'Angelo (2006 apud GALHANONE, 2008, p. 10), "o luxo é uma invenção social, uma criação do homem. É um conjunto de significados atribuidos a determinados objetos e atividades. Nada é intrinsecamente luxuoso; é preciso que assim seja chamado".

Assim, pode-se afirmar que todo consumo é cultural, visto que sempre envolve um processo de significação: temos necessidades e agimos em função delas compreendendo sensações, experiências e circunstâncias para dar sentido e modificar objetos. Para Slater (2002), o ato de consumo envolve significados que são partiIhados no meio social. Quando usamos os códigos de consumo de nossa cultura, assim, segundo esse autor, por meio do consumo de objetos de luxo, reproduzimos e demonstramos nossa participação em uma determinada estrutura social.

Os significados dos bens de consumo, como nos coloca McCracken (2003), podem ser fascinantes por se estabelecerem como suportes do significado cultural e como oportunidade para definição de si e do mundo. Os bens de luxo mostram-se ainda mais fascinantes, pois auxiliam na definição de um eu e de um mundo melhor, encantador, extraordinário. Assim, podemos afirmar que os consumidores não compram simplesmente produtos, "eles adquirem imagens percebidas de um mundo onde possam habitar, interagir e, principalmente, sentir-se extremamente confortáveis em sua própria pele" (GARCIA; MilRANDA, 2005, p. 114).

Além disso, segundo Galhanone (2008), existe uma certa expertise cultural que envolve o consumo de luxo e é necessária para que o indivíduo possa verdadeiramente apreciar os produtos desse mercado. Os consumidores do luxo precisam ter conhecimento das regras de consumo e de sua utilização para a formação de um gosto pessoal diferenciado, algo que se aprende, basicamente, pelo compartilhamento de conhecimentos nos meios sociais de origem e socialização.

Em uma lista mais sucinta, Appadurai (1986 apud STREHLAU, 2004) e GaIhanone $(2008$, p. 13) destacam como atributos dos objetos de luxo: o consumo restrito em razão do preço elevado ou de restrições legais; a complexidade de aquisição, decorrente da escassez; a virtude semiótica (capacidade de sinalizar corretamente mensagens sociais); o conhecimento especializado, pré-requisito para o consumo apropriado; e o alto grau de relacionamento do consumo com o corpo, a pessoa e a personalidade. 
Assim, com esse arrazoado teórico, não se pretendeu atribuir um significado ao termo luxo, pois poderia ser apenas uma definição vaga, já que o conceito de luxo, como demonstrado acima, é histórico, extremamente multifacetado e subjetivo. A intenção desses primeiros argumentos exibidos é apresentar as ideias existentes para o leitor como meio de colocá-lo a par das dimensões da imaterialidade e da subjetividade que rondam a conceituação do que é luxo, para que assim se possa seguir com as considerações sobre popular, contudo, isso será feito a partir da metodologia de pesquisa apresentada a seguir.

\section{Metodologia}

Para esta pesquisa, adotou-se uma abordagem de natureza qualitativa, utilizando como método de procedimento o conjunto de fases do Meid ${ }^{8}$ Método Exploratório de Intervenção do Design - proposto por M. T. LOPES (2013), contudo usando apenas a fase dos mapeamentos, pois não houve interesse, até esse ponto da pesquisa, pelo desenvolvimento de novos objetos e sim o de fundamentar as bases discursivas e teóricas que subsidiam a discussão para a ação de criar novos objetos de moda no Agreste pernambucano.

A escolha por esse modelo de pesquisa deu-se porque ele versa sobre o entendimento do design, para além da condição de disciplina, e o abraça como um fenômeno cultural. Nesse sentido, ele colabora para que a compreensão esteja propositadamente à mercê da apropriação simbólica e significativa da diversidade e da complexidade dos variados contextos socioculturais construídos materialmente pelo homem (LOPES, 2014).

0 Meid possibilitou uma imersão no universo das marcas e uma ordenação destas enquanto produtoras de materialidades, entendendo suas linguagens gráfica e visual, observando como elas se organizam para dar sentido aos discursos e poder, assim, entender como luxo e popular se transformam em objetos pelos designers da capital pernambucana.

Dessa forma, a tabela abaixo resume o entendimento de como a pesquisa se desenvolveu com base no Meid e quais os resultados obtidos em cada fase realizada:

\section{Tabela 1 - Metodologia da pesquisa}

\section{Levantamento bibliográfico \\ Criação do mapa das referências bibliográficas. Os temas centrais abordados foram as definições de luxo, popular, cultura de consumo, design, inovação e significação e o entendimento do campo teórico que articulam. \\ Fase da pesquisa: 1.1. Mapeamento da ordem subjetiva [Meid] \\ Resultados obtidos: Foram feitas análises de discurso e de filtro bibliográ- fico sob a ordenação de quatro conceitos propostos pelo Meid, sendo eles discurso, imaginário, espírito do tempo e materialização ${ }^{9}$, que possibilitaram a ampliação do conhecimento referente ao luxo e à sua relação com o de- sign e esclarecer o design de moda como um processo de impregnação de significado sobre os artefatos.}

Fase da pesquisa: 1.2. Mapeamento social implícito ao design [Meid] 
Resultados obtidos: Também foram feitas análises sob a ordenação de conceitos propostos pelo Meid, sendo eles as especialidades do design, a cultura, a economia, a tecnologia e o meio ambiente, que possibilitaram uma melhor apreensão do meio social no qual o design se faz presente e das ações mútuas exercidas por esses conceitos que influenciam o processo de fazer design.

\section{Atividade de campo}

Aproximação com o objeto da pesquisa, os designers recifenses, para entender como se dá seu discurso em verbo-visual e como é organizada sua produção de objetos de moda.

Fase da pesquisa: 2.1. Mapeamento iconográfico [Meid]

Resultado obtido: Registro de imagens e vídeo em cada entrevista realizada, obtendo, assim, um banco de dados com mais de 200 imagens que ainda estão sendo estudadas.

Fase da pesquisa: 2.2. Mapeamento dos fundamentos da linguagem gráfica [Meid]

Resultado obtido: Criação de um banco de dados imagético, de acordo com a catalogação das imagens da fase anterior, sob a classificação dos fundamentos da LG (cor, textura, imagens, tipografia e esquemas), contendo fotos dos produtos, das relações de produção e das lojas/ateliês, para possibilitar a compreensão da ação discursiva desses entrevistados sob a materialidade trabalhada por eles, articulando assim o discurso visual referente a cada marca.

\subsection{Entrevista semiestruturada por questionário}

Resultado obtido: Aplicação do questionário ${ }^{10}$ para o registro dos atos de fala dos entrevistados e posterior análise do discurso e dos vídeos e fotos realizados. Foi possível não só entender como ocorre o processo de significação dos designers por meio de seus produtos, mas também conhecer as tendências de mercado, as estratégias de produção, os valores regionais e pessoais, a mudança de paradigmas, a valorização do processo artesanal, do produto criativo e da inovação, entre outros fatores.

3. Análise dos dados

Método: Análise do discurso

Resultado obtido: Entendimento aprofundado, a partir da coleta dos atos de fala dos designers recifenses, de como eles compreendem a dimensão de popular e de luxo em seus objetos e nas práticas profissionais para a criação.

Análises e inferências para a significação de luxo e de popular para os designers recifenses

Para apresentar as considerações finais é interessante relembrar a pergunta da pesquisa, ponto de partida para nossa investigação: como os designers recifenses significam material e discursivamente os conceitos de luxo e de popular em 
seus trabalhos de moda? A resposta geral encontrada explica que eles fazem isso de maneira variada e de acordo com a trajetória de cada marca, porém, igualam-se em discurso, quando se trata dos conceitos de exclusividade, qualidade e originalidade, de maneira que cada empresa busca isso de forma acumulativa ao seu branding e aos seus produtos, e como recurso simbólico para se afirmar e firmar como marca de moda.

Entretanto, o entendimento acima apenas resume a discussão articulada. Assim, para apresentar com profundidade os achados da pesquisa, foram estruturados sete pontos discursivos que os explicam de forma mais aprofundada e que a seguir apresentamos por tópicos.

\section{A maioria das confecções é de pequeno porte e com abrangência de significação local}

As empresas entrevistadas, apesar de a maioria ser de pequeno porte, mostraram um movimento recorrente de expansão, ampliado principalmente via redes sociais (Facebook e Instagram), e também têm uma boa parte de suas vendas feitas a partir do e-commerce, de seus próprios sites ou de sites terceirizados. Essas marcas mostraram-se bastante atentas a esse tipo de relação com o cliente e são muito interessadas em produzir uma imagem on-line.

Entre elas, apenas uma das lojas visitadas apresentava uma fábrica maior, porém, é importante lembrar que entre as empresas que não foram entrevistadas mas são igualmente importantes na produção recifense e, consequentemente, para esta pesquisa -, duas também possuíam grandes fábricas e uma delas é conhecida e reconhecida como marca de moda também em outros estados brasileiros.

Dessa forma, pode-se entender que, apesar de o Recife ser a capital do Estado de Pernambuco e sua situação geopolítica sugerir um status como deflagrador das tendências de comportamento de moda para a região, essas tendências não migram de forma direta para o interior. Além disso, foi possivel observar que a cidade não possui um polo produtor de produtos de moda, como as cidades da região Agreste que compõem o APL - Confecção (Arranjo Produtivo Local de Confecção).

0 que podemos, no entanto, apontar como um movimento de significação para o campo da moda no Recife é o que cunhamos de "Movimentação de Autoralidade Material" e definimos como ações de proposição de estilo e busca autoral a partir do domínio e do saber fazer sob uma materialidade significante. Mas isso não configura a cidade como um polo de estilo, pois não há uma ação geral de grupo e coletividade e orquestrada que seja organizadora da trajetória dessas marcas, o que há é a ação individual de cada empresário, e muito em consequência disso, o alcance de significado dessas marcas não é global e sim local.

\section{A maioria dos ateliês busca se inserir na categoria do novo luxo}

0 novo luxo, como já foi explicitado anteriormente, pode ser visto como um novo segmento do mercado de luxo que surgiu por causa da grande demanda do mercado atual, com consumidores que buscam, além de prestígio social, produtos de qualidade, exclusivos e não tão caros. Essa nova fatia do comércio relaciona-se com uma nova psicologia de consumo, que transcende o objeto e valoriza principalmente as experiências.

A presença de lojas inseridas no padrão do novo luxo e consumidores que buscam esse tipo de produto é algo positivo, pois indica também certa maturidade do mercado recifense, já que, segundo Cardoso, à medida que um mercado amadurece, os consumidores passam a querer produtos mais individualizados "customizados", no jargão da indústria (CARDOSO, 2011, p. 106).

Entre as empresas entrevistadas não encontramos nenhuma que se pronunciou como inserida no mercado de luxo propriamente dito. Elas não afirmam isso em seu discurso, mas seus atos de fala, ao serem analisados, permitiram o entendimento de que algumas, sem muita consciência, trazem para si esse conceito. Ocorrendo, em sua maioria, empresas que apresentam produtos mais caros ou elaborados, assim 
como também existem aquelas que comercializam itens mais baratos e têm como público as classes $C$ e $D$, mas criam um campo de aspiração para a sua marca a partir do oferecimento da relação de qualidade nos artefatos fabricados por elas.

\section{A exclusividade é o luxo recifense}

A palavra exclusividade aparece no discurso de todos os entrevistados quando são questionados sobre como significam luxo nos artefatos que produzem. Dessa forma, atribuimos a esse termo o status de caracteristica primordial para eleger, no caso do mercado recifense, se um produto é luxuoso ou não. Claro que não devemos nos ater apenas a essa característica, mas, digamos, que ela ocuparia a primeira colocação em uma lista de qualidades necessárias aos objetos de luxo recifenses.

Até mesmo o pequeno porte das empresas sustenta a exclusividade como caracteristica marcante, visto que a pequena produção - se as compararmos com as grandes marcas de varejo como C\&AA, Riachuelo e Zara - garante aos produtos um quê de diferenciação. É importante notar também que todas as lojas em questão procuram produzir objetos originais, ligados às tendências atuais da moda, que não são meras cópias das grandes marcas.

Além da busca pela exclusividade por meio da consolidação de uma identidade e de um estilo próprios, algumas marcas também vêm se especializando em uma materialidade especifica, tornando-se experientes e cada vez melhores dentro do nicho que dominam. 0 que é reforçado pelo fato de que as marcas criaram uma trajetória de domínio de materialidade, fato muito importante quando se estrutura um caminho para se consagrar como uma marca de luxo.

Como exemplos de materialidades trabalhadas pelos ateliês recifenses, podemos citar a renda renascença, o acrílico, a estamparia digital, o linho, o couro, 0 arame e o cadarço. 0 que se pode observar é que, independentemente dos tipos de materiais utilizados, é o saber fazer, a especialização dentro de um mercado tão amplo, que também confere um status de exclusividade aos produtos. Abaixo, são apresentados alguns artefatos de produtores recifenses.

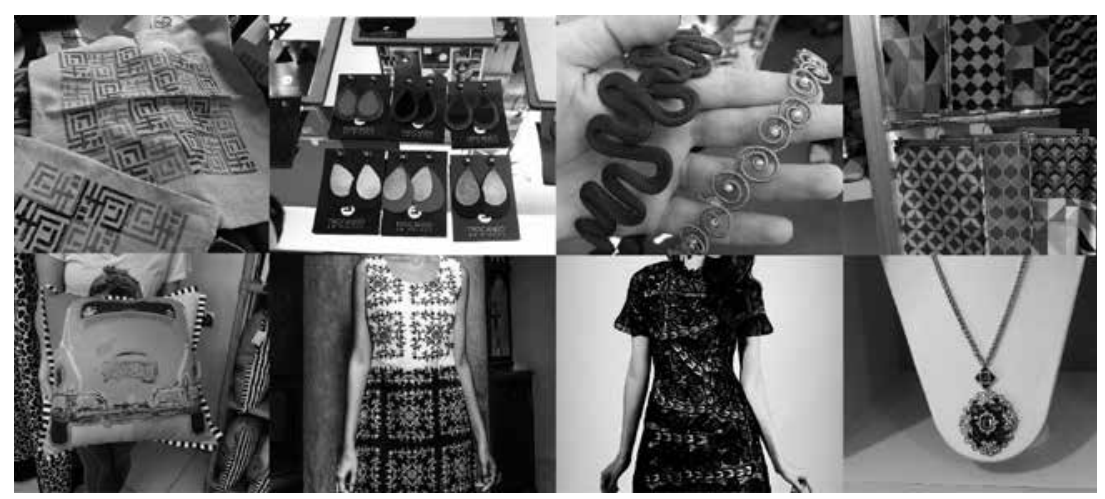

Figura 1 - Materialidade recifense. Da esquerda para a direita: as marcas Desalinho (linho e estamparia artesanal), Trocando em Miúdos (acrílico), Maria Ribeiro (arame e cadarço), Duas Design (estamparia digital), Casa 87 (estamparia digital), Club Noir (variados tipos de tecido), Noemy Rendas (renda renascença) e Joana Franco (bijuterias).

Para os designers recifenses, ser exclusivo é algo que organiza um sistema de distinção que os significa e, nesse processo, o domínio de um saber fazer ligado a uma dada materialidade denota que eles estão em um caminho muito interessante, o de ser exclusivo adquirindo, em sua trajetória, autoridade e autoria e organizando isso no campo da materialidade que eles identificam ser significante para o segmento em que estão, imprimindo nela a sua proposta de design. 
Essas marcas desenvolvem objetos de design de moda por meio de uma estrutura conceitual que extraem do campo utópico de significação de suas marcas (branding) e para realizá-lo, torná-lo tangivel e também objeto de consumo, constroem habilidades práticas e domínios materiais e metodológicos para fazer inferências significativas nas formas e superficies dos objetos que produzem, por exemplo, o corte, o molde e o encaixe do acrílico, a estampa no linho, o entrelaçar do arame, e quando esse objeto está pronto oferece a seus consumidores um discurso visual próprio/exclusivo, que lhes permite também o sentimento de exclusividade, unicidade e distinção, só que agora como argumento material para a constituição das suas aparências.

Esse domínio da materialidade é algo muito interessante no contexto da moda pernambucana, pois muitas marcas internacionais se consagram fazendo o domínio de materialidades mais globais, como a malha e o jeans, com as quais a indústria e o comércio já estão organizados para fazer e comercializar, respectivamente. Já essas marcas do Recife construiram, por espírito do tempo", um comportamento de moda autoral recorrente, por meio da busca por notoriedade por domínio de materialidade.

\section{Não dissociação consciente entre luxo e popular na produção}

Os designers das lojas entrevistadas não apresentavam em seus discursos, nem em sua criação, uma preocupação em fazer uma diferenciação do que seria luxo e popular porque para eles o mais importante é, acima de tudo, fabricar artefatos de qualidade - independentemente do preço. Discursivamente, eles entendem que precisam apresentar qualidade em todas as etapas do processo de produção de uma peça (planejamento, produção e venda), e que esta precisa revelar a identidade da marca.

0 que existe dentro da produção dos ateliês são produtos mais caros ou mais baratos, mais simples ou mais complexos, linhas mais básicas ou mais elaboradas que coexistem ou se alternam dentro do mesmo espaço, da mesma empresa, com a intenção de atender perfis diferentes de clientes.

As empresas recifenses selecionadas, portanto, não têm como um de seus objetivos a sua inserção no mercado do luxo. Elas estão, na verdade, mais preocupadas em se fixar como marcas, em construir uma identidade forte e realçar essa identidade naquilo que elas produzem. Algumas também já apresentam um discurso mais sustentável quando mostram preocupação com os materiais que usam e com o não desperdício deles.

Contudo, a partir do que fora dito, pode-se inferir que o entendimento do luxo aqui proposto funciona como um corte de significação interessante para essas marcas, no sentido de elas pensarem senão a sua produção, mas pelo menos algumas linhas ou alguns segmentos de produtos, no intuito de criar o novo, organizar essa relação de luxo como um argumento possivel para o branding da marca.

Assim, o luxo funciona como uma força significante externa à marca e teria a função de algo que a obriga a repensar sua produção, que a impele ao novo e ao distintivo dos demais itens produzidos e consumidos por seus clientes, já que o saber fazer para a criação de objetos autorais, distintivos e exclusivos a marca já domina.

\section{Popular visto de várias formas}

Como já explicitado na análise dos discursos, o termo popular despertou diferentes visões entre os entrevistados, sendo as três principais: como produção em massa e, consequentemente, produtos mais baratos, popular e moda (moda como poder de popularizar tendências) e um viés do regionalismo (popular ligado àqueles objetos caracteristicos de um povo ou de uma cultura, produzidos geralmente por artesãos de uma região). 
A grande maioria dos ateliês não apresenta apenas uma visão sobre popular, eles têm o entendimento de que o popular expressa-se de várias formas, e como produto pode ser algo com um custo mais baixo ou não. Também não revelam, em seu discurso, características de inquietação ou desagrado quanto aos produtos mais baratos, enxergam como um nicho do mercado que precisa existir para atender a outras classes ou a outros interesses dos clientes.

Contudo, esses designers mostram uma peculiaridade nessa discussão sobre o popular, pois eles valorizam bastante a cultura popular pernambucana, muitos recorrem a ela como campo de inspiração e festas como o Carnaval e o São João são ordenadoras de novos objetos, que tomam como base criativa significante 0 adornar-se caracteristicamente para se comemorar essas festividades. E essas marcas embarcam nessas festividades como recurso para se significarem.

Mas é algo interessante destacar a ausência de ateliês no interior do Estado, visto que essa expressão popular é bem forte nessa região. Longe de ser uma cobrança, mas é algo que fora observado na pesquisa: a cultura popular é, na maioria dos casos analisados, entendida como arte e assim aproxima-se do campo do luxo, como algo de muito valor, mas produzir onde ela ocorre mais fortemente, ainda não é um ambiente empreendedor, seguro e favorável para essa dimensão do design local.

\section{Há o reconhecimento do valor do design como diferencial}

Entre os donos dos ateliês, existem pessoas com mais de uma formação, que possuem outra especialidade que não o design e depois se encontraram dentro do mercado da moda, e para se apropriar melhor desse conhecimento realizaram um curso voltado à área ou algum tipo de especialização. Também temos aquelas pessoas que não são designers, mas vieram de uma área de formação na qual também há uma valorização do processo projetual, como a arquitetura e a engenharia.

Contudo, a maioria dos ateliês entrevistados tem como fundadores/donos designers, podendo ser do campo do design de moda ou não, e acreditamos que, principalmente por causa desse fato, as lojas que foram entrevistadas demonstraram reconhecimento do design como atividade diferenciadora e essencial na fabricação de artefatos, sendo citado, muitas vezes, como conhecimento agregador de valor.

Esse fato é reflexo de que, durante as décadas de 1990, 2000 e 2010, a quantidade de novos cursos de design, que passou de um para oito em todo o Estado, deixou como consequência uma massa crítica e criativa atuante no campo do design, que está concentrada na capital, pois desses oito cursos apenas dois estão no interior, que se somam a uma história política de governo municipal e estadual de valorização cultural popular e regional, e que hoje dão sentido à adoção da perspectiva global da economia criativa, como um campo de interesse e desenvolvimento para Pernambuco.

\section{Preocupação com a produção local}

Na nossa última assertiva, podemos concluir dizendo que as marcas recifenses estavam, entre 2013 e 2015, em um caminho de expansão da valorização do produto local, pois, em seus discursos, percebemos certa preocupação em comunicar seus produtos como locais, mostrando ao cliente que ele não precisa buscar em outras regiões objetos de qualidade. Na própria cidade é oferecido o exemplo de uma loja colaborativa, na qual várias marcas recifenses se juntaram para vender, em um mesmo espaço, seus produtos, e assim fortalecer o elo entre elas e aumentar a divulgação dos ateliês. 
Esse interesse pelo local é explicado por Hall:

\begin{abstract}
Há, juntamente com impacto do "global", um novo interesse pelo "local". A globalização (na forma da especialização flexivel e da estratégia da criação de "nichos" de mercado), na verdade, explora a diferenciação local. Assim, ao invés de pensar o global como substituindo o local seria mais acurado pensar numa nova articulação entre o "global" e "o local". Este "local" não deve, naturalmente, ser confundido com velhas identidades, firmemente enraizadas em localidade bem delimitadas. Em vez disso, ele atua no interior da lógica da globalização. (HALL, 2014, p. 45)
\end{abstract}

A partir dessa fala de Hall (2014), pode-se apontar para o fato de que Recife já se insere nessa lógica da globalização, na qual os produtores locais estão sendo mais valorizados, e, ao mesmo tempo, preocupam-se em expandir suas fronteiras não apenas como marca local, mas usando dessa caracteristica em sua identidade como uma forma de diferenciação no campo da moda.

Contudo, o que esta pesquisa aponta é que seria interessante - tanto nas ordens pública, legal e governamental, quanto nas privada e empreendedora - se atinar para o diálogo local X local, que no caso estudado configura-se como capital e interior, como um espaço interessante para inovação e pouco explorado pela dinâmica da economia criativa, pois ele pode ser entendido como um "ambiente metabólico" ${ }^{12}$ para o desenvolvimento de novos sentidos para o campo do design de moda em Pernambuco.

Criar estradas, pontes e viadutos foi estrutural: a chegada da Universidade Federal de Pernambuco (UFPE) foi significativa e agora significante, contudo sistemas de comunicação, redes de relacionamentos, parcerias institucionais públicas e privadas e, principalmente, as pessoas que fazem design, arte e artesanato precisam se conhecer e se relacionar. Mais do que campo de inspiração, o Agreste hoje é campo e mercado para o desenvolvimento do design de moda no Estado, não necessariamente de moda autoral, mas de organização e produção desse tipo de objeto.

Novos objetos são importantes para evitar o exagero da cópia e a ilegalidade dela, portanto, é algo ordenador, mas o principal para se construir novos sentidos é o rearranjo de novos tipos de relações humanas entre a capital e o Agreste. Nesse sentido, este estudo aponta que a pesquisa em e para inovação é uma vertente interessante, pois ela pode criar encontros e interesses em comum, revelar novas formas de agir e possibilitar a circulação e a construção de novos conhecimentos, espaços e designers para esse saber. Contudo, o GeFol (Grupo de Pesquisa em Formação do Olhar criado por LOPES em 2014) destaca que para se inovar é preciso também que haja um desejo e um campo de expectativa nas pessoas para esse novo. Pois, para nós, inovar é mudar de sentido.

A crise econômica, política e democrática atual vai gerar uma reordenação dessa realidade elencada pelo estudo no Agreste, e a inovação que hoje, mais do que um lócus discursivo, é política pública ${ }^{13}$ e será um vetor muito forte para novas significações no design de moda se as pessoas que constroem esse campo assim a articularem, não somente de forma discursiva, mas como prática real, individual e coletiva.

\title{
Consideraç̧ões finais
}

Assim, pode-se concluir afirmando que a relação entre luxo e popular é uma dimensão de significação da moda para a cidade do Recife, e cujos conceitos não são dissociados para os designers recifenses, algo que é popular 
pode sim ter valor de luxo, se esse algo se organizar material e simbolicamente por meio da exclusividade de estilo e aparência e da qualidade de sua produção. Nesse sentido, os designers da cidade, ainda que empiricamente, tendem a estabilizar a moda recifense como uma proposição de estilos que se aproximam do novo luxo (global) e dialogam com o conceito de popular como um investidor de identidade (local), como algo valorativo aos seus artefatos, não como algo que os deprecia.

Contudo, o popular que esses designers propõem é algo particularizado pelo branding de cada marca, e não uma cópia da cultura popular nordestina, ou mesmo algo sem qualidade - o estágio desse conceito de popular seria algo próximo do que Canclini (1989) propõe como desconstrução desse conceito para que, posteriormente, e nesse caso em cada marca, se construa uma nova significação do sentido de popular, mas incorporado ao novo que cada marca dessas representa com seus objetos, notadamente, como significante dentro da cultura visual.

0 popular para os designers recifenses não é algo subalterno ao hegemônico, mas algo que permite a eles a distinção dos demais e que os configura como únicos. É certo que é cedo para afirmar, mas, futuramente, ao se analisar a trajetória dessas marcas como história da moda pernambucana, esse movimento de aproximação do novo luxo, poderá se ver que, aos poucos e muito lentamente, elas estão (re)significando o valor de popular e assim estão (re)significando os valores estéticos vigentes na região, atualizando-os e criando cultura visual da sua época. 


\section{NOTAS}

[1] Esse termo define os indivíduos que participaram da pesquisa, em um número total de 24. Eles se caracterizaram assim por terem alguma formação no campo do design ou em áreas dialógicas, como a arquitetura, são empresários e possuem loja/ateliể de produtos de moda na cidade do Recife e cuja produção foi comercializada há pelo menos um ano na região.

[2] No GeFol, o conceito de inovação é definido por dois marcos, um primeiro legal, apoiado na Lei 13.243 , de janeiro de 2016, que entende o desenvolvimento social como argumento para inovar, notadamente em regiões como o Agreste; e outro epistemológico, pautado na semiótica darrasiana, que se utiliza do ciclo completo de mudança de hábito, mais precisamente do conceito de relógio de metabolismo, para propor que inovar é produzir novos hábitos e com eles novos campos de significação e novos sistemas de sentido.

[3] Usamos a definição de LOPES, M.T. (2014) e LOPES, M.T. (2016), em que a autora diz que tomando-se Foucault como referência, começa a ser definido como todos os demais discursos, ou seja, como um ato humano para a sistematização de um organismo de significados, que para existir ancora-se em um campo de poder simbólico disciplinar e sobre os sombreamentos prováveis e possiveis com os demais campos.

${ }^{[4]}$ Relação entre as dimensões de significação e práticas em geral entre o global e o local.

[5] É uma relação de análise na qual se objetiva entender como ocorre a produção de sentidos em torno de um ou mais conceitos, articulando a análise do discurso como método para a extracão de significados, mas podendo recorrer à semiótica ou à semiologia para a estruturação das extração dos sentidos do dado contexto analisado.

${ }^{[6]}$ Disponivelem:<http://michaelis.uol.com.br/modemo/portugues/index.php?lingua=portuques-portuques\&tpalavra=popular> . Acesso em: 14 abr. 2016.

[7] 0 termo distinção aqui será utilizado na acepção de Bourdieu (2007).

${ }^{[8]}$ Meid consiste em um modelo de ensino e aprendizagem de design, que pode ser vivenciado pelo sujeito em formação, como uma proposta de disciplina e metodologia de pesquisa e/ou projetual, pois sua vivência vai depender da abordagem andragógica para a qual ele for direcionado. Sua essência formadora está em aprender a fazer design quem não é designer, com o compartilhamento de informacões, o convivio e a parceria com diversos grupos sociais, ambientes e instituições públicas e grupos de expressões de contracultura, possibilitando a compreensão da dimensão social dos objetos de design.

${ }^{[9]}$ Esses quatros conceitos são definidos pelo Meid a partir da conceituação dos autores seguintes: para discurso, fora apresentado o conteúdo da análise do discurso sob uma perspectiva foucaultiana; para a discussão sobre o imaginário foram trazidos Ono (2004) e Ferreira e Orrico (2002): para o entendimento de materialização foi adotada a perspectiva de Cardoso (1998); e para espírito do tempo, Edgar Morin (2011) e Stuart Hall (2006).

[10] Questionário: Nome, Marca, Contato. 1. Tempo de mercado? 2. 0 que é luxo para você? 3. Como você retrata o luxo nos artefatos que produz? 4. Existe algum material que você sempre utiliza quando quer representar o luxo em seus produtos? 5.0 que é popular para você e como você o retrata nos artefatos que produz? 6. Existe algum material ou figura que você utiliza quando quer representar o popular em seus produtos? 8. Na sua opinião, algo que é popular pode ser ou vir a ser um luxo?

${ }^{[11]}$ Ou Zeitgest. Termo de origem alemã significa, em resumo, o conjunto do clima intelectual e cultural do mundo em uma determinada época, as características genéricas que surgem e definem certo período histórico.

${ }^{[12]}$ DARRAS (2012).

[13] Lei n. 13.243, de 11 de janeiro de 2016. Disponivel em: http://www.planalto.gov.br/ccivil_03/_ato20152018/2016/lei/l13243.htm>. Acesso em: 25 mar. 2016. 


\section{REFERÊNCIAS}

BOURDIEU, P. Distinção: a crítica social do julgamento. São Paulo: Zouk, 2007.

CANCLINI, Nestor. Culturas híbridas. 4a ed. SP: Edusp, 1998, 385 p.

CARDOSO, R. Design para um mundo complexo. 1ª ed. São Paulo: Cosac Naify, 2013, 262 p.

CARDOSO, Rafael [Denis]. Design, cultura material e o fetichismo dos objetos. Revista Arcos. Design, cultura material e visualidade. Rio de Janeiro, v. 1, número único, pp. 14- 39, out. 1998.

CASTARĖDE, J. O luxo: segredo dos produtos mais desejados do mundo. São Paulo: Barcarolla, 2005.

CATENACCI, Vivian. Cultura popular: entre a tradição e a transformação. São Paulo Perspec., São Paulo" v. 15, n. 2, 2001.

DARRAS, Bernard. Ensaio de modelização geral das relações humanas com os artefatos. Estudo semiótico e sistêmico das interações. Conferência para o Seminário de Pesquisa em Design de Informação. UFPE: Recife, outubro, 2012.

GALHANONE, Renata. Atitudes, emoções e comportamento de compra: um estudo com consumidores de produtos de luxo ou sofisticados. São Paulo, 2008, 259 p.. Dissertação (Mestrado) - Universidade de São Paulo.

GARCIA, Carol; MIRANDA, Ana Paula de. Moda e comunicação: experiências, memórias e vínculos. São Paulo: Anhembi Morumbi, 2005.

FOUCAULT, Michel.. A ordem do discurso. Aula inaugural no College de France, Pronunciada em 2 de dezembro de 1970. Tradução: Laura Fraga de Almeida Sampaio. São Paulo: Edições Loyola, 2002.

HALL, Stuart. Da diáspora: identidades e mediações culturais. Brasilia: UNESCO, 2003, 434 p.

A identidade cultural na pós-modernidade. Rio de Janeiro: Lamparina, 2014

LIPOVETSKY, Gilles; ROUX, Elyette. O luxo eterno: da idade do sagrado ao tempo das marcas. São Paulo: Companhia das Letras, 2005.

LOPES, Maria Teresa. Apresentação e discussão dos modelos exploratórios de intervenção de design -

Meid: a ação em parceria como metodologia para o desenvolvimento da formação acadêmica em design. Anais do $9^{\circ}$ colóquio de moda - $8^{a}$ edição internacional 2013.

Uma formação do olhar: o design da informação como conteúdo formador dos professores das licenciaturas brasileiras. UFPE, Recife: 2014. Mimeo. p. 499.

McCRACKEN, G. Cultura e consumo: novas abordagens ao caráter simbólico dos bens e das atividades de consumo. Rio de Janeiro: MAUAD, 2003.

MORIN, Edgar. Cultura de massa no século XX: o espírito do tempo. Paris: Grasset, 1962.

ORTIZ, Renato. Cultura brasileira \&t identidade nacional. 5. ed. São Paulo: Editora Brasiliense, 1994.

SANTOS, José Luiz dos. 0 que é cultura. 16ª ed. São Paulo: 1996, 91 p.

STREHLAU, Suzane. 0 luxo falsificado e suas formas de consumo. São Paulo, 2004, 307 p. Tese

(Doutorado) - Fundação Getúlio Vargas.

TORACl, Tatiana. Tiaras são para sempre: significação de luxo na vida cotidiana. Recife, 2010, 115 p.

Dissertação (Mestrado) - Faculdade de Boa Viagem. 